\title{
FIXED POINTS OF DISCONTINUOUS MAPPINGS IN UNIFORMLY CONVEX METRIC SPACES
}

\author{
SAMI ATIF SHUKRI*, VASILE BERINDE** AND ABDUL RAHIM KHAN*** \\ *Department of Mathematics \\ Amman Arab University, Amman 11953, Jordan \\ E-mail: samishukri@yahoo.com \\ **Department of Mathematics and Computer Science, Technical University of Cluj-Napoca, \\ North University Center at Baia Mare, Victoriei 76, 430221 Baia Mare, Romania \\ E-mail: vberinde@cunbm.utcluj.ro \\ ***Department of Mathematics and Statistics \\ King Fahd University of Petroleum and Minerals, Dhahran, Saudi Arabia \\ E-mail: arahim@kfupm.edu.sa
}

\begin{abstract}
Some fixed point theorems for discontinuous mappings in Banach spaces by Berinde and Păcurar [Fixed point theorems for non-self single-valued almost contractions, Fixed Point Theory 14 (2013), 301-311] and Kirk [Fixed point theorems for non-Lipschitzian mappings of asymptotically nonexpansive type, Israel J. Math. 17 (1974), 339-346] are extended to uniformly convex metric spaces.

Key Words and Phrases: Fixed points, hyperbolic metric space, uniformly convex metric space, asymptotically nonexpansive mapping, non-Lipschitzian mapping, non-self almost contractions. 2010 Mathematics Subject Classification: 47H09, 47H10, 46B20.

Acknowledgment. The paper was written during the visit of second author of the Department of Mathematics and Statistics, King Fahd University of Petroleum and Minerals, Dhahran, Saudia Arabia. The authors A.R. Khan and S.A. Shukri are grateful to King Fahd University of Petroleum and Minerals for supporting the research project IN121023.

The second author is grateful to Professor Ioan A. Rus for providing extremely useful comments on a previous version of the manuscript and drawing his attention to [13] which points out that the set of elements $y$ satisfying equation (??) might be empty.
\end{abstract}

\section{REFERENCES}

[1] N. A. Assad, A fixed point theorem for some non-self-mappings, Tamkang J. Math., 21 (1990), 387-393.

[2] V. Berinde, Approximation fixed points of weak contractions using the Picard iteration, Nonlinear Anal., 9 (2004), 43-53.

[3] V. Berinde, M. Păcurar, Fixed point theorems for nonself single-valued almost contractions, Fixed Point Theory, 14(2013), 301-311. 
[4] V. Berinde, M. Păcurar, The contraction principle for nonself mappings on Banach spaces endowed with a graph, J. Nonlinear Convex. Anal., 16(2015), 1925-1936.

[5] M. Bridson, A. Haefliger, Metric Spaces of Non-positive Curvature, Springer-Verlag, Berlin, Heidelberg, New York, 1999.

[6] F.E. Browder, Nonexpansive nonlinear operators in a Banach space, Proc. Nat. Acad. Sci. U.S.A., 54(1965), 1041-1044.

[7] R.E. Bruck, Y. Kuczumow, S. Reich, Convergence of iterates of asymptotically nonexpansive mappings in Banach spaces with the uniform Opial property, Colloq. Math., 65(1993), 169-179.

[8] F. Bruhat, J. Tits, Groupes réductifs sur un corps local. I. Données radicielles valuées, Inst. Hautes Études Sci. Publ. Math., 41(1972), 5-251.

[9] H. Busemann, Spaces with non-positive curvature, Acta. Math., 80(1948), 259-310.

[10] Lj. B. Ćirić, A remark on Rhoades's fixed point theorem for non-self mappings, Internat. J. Math. Math. Sci., 16 (1993), 397-400.

[11] P. Collaço, J. Carvalho e Silva, A complete comparison of 25 contraction conditions, Nonlinear Anal., 30(1997), 741-746.

[12] S. Dhompongsa, W.A. Kirk, B. Sims, Fixed points of uniformly lipschitzian mappings, Nonlinear Anal., 65(2006), 762-772.

[13] J. Eisenfeld, V. Lakshmikantham, Fixed point theorems on closed sets through abstract cones, Appl. Math. Comput., 3(1977), 155-167.

[14] K. Goebel, W.A. Kirk, A fixed point theorem for asymptotically nonexpansive mappings, Proc. Amer. Math. Soc., 35(1972), 171-174.

[15] K. Goebel, S. Reich Uniform Convexity, Hyperbolic Geometry, and Nonexpansive Mappings, Series of Monographs and Textbooks in Pure and Applied Mathematics, Vol. 83, M. Dekker, New York, 1984.

[16] K. Goebel, T. Sekowski, A. Stachura, Uniform convexity of the hyperbolic metric and fixed points of holomorphic mappings in the Hilbert ball, Nonlinear Anal., 4(1980), 1011-1021.

[17] D. Göhde, Zumprinzip der kontraktiven Abbildung, Math. Nachr., 30(1965), 251-258.

[18] M.A. Khamsi, On asymptotically nonexpansive mappings in hyperconvex metric spaces, Proc. Amer. Math. Soc., 132(2004), 365-373.

[19] M.A. Khamsi, A.R. Khan, Inequalities in metric spaces with applications, Nonlinear Anal., 74(2011), 4036-4045.

[20] W.A. Kirk, A fixed point theorem for mappings which do not increases distances, Amer. Math. Monthly, 72(1965), 1004-1006.

[21] W.A. Kirk, Fixed point theorems for non-Lipschitzian mappings of asymptotically nonexpansive type, Israel J. Math., 17(1974), 339-346.

[22] W.A. Kirk, A fixed point theorem in $C A T(0)$ spaces and $\mathbb{R}$-trees, Fixed Point Theory Appl., 4(2004), 309-316.

[23] W.A. Kirk, Geodesic geometry and fixed point theory II, In: J. Garcia Falset, E. Llorens Fuster, B. Sims (eds.), International Conference on Fixed Point Theory and Applications (Valencia, 2003), Yokohama Publ., Yokohama, 2004, 113-142.

[24] U. Kohlenbach, L. Leustean, Asymptotically nonexpansive mappings in uniformly convex hyperbolic spaces, J. Eur. Math. Soc., 12(2010), 71-92.

[25] K. Menger, Untersuchungen über allgemeine Metrik, Math. Ann., 100(1928), 75-163.

[26] S. Reich, I. Shafrir, Nonexpansive iterations in hyperbolic spaces, Nonlinear Anal., 15(1990), 537-558.

[27] B.E. Rhoades, A fixed point theorem for some non-self-mappings, Math. Japon., 23(1978/79), 457-459.

[28] I.A. Rus, The generalized retraction methods in fixed point theory for nonself operators, Fixed Point Theory, 15(2014), 559-578.

[29] I.A. Rus, M.-A. Şerban, Some fixed point theorems for non self generalized contractions, Miskolc Math. Notes, 17 (2017), No. 2, 1021-1031.

[30] M.-A. Şerban, Some fixed point theorems for nonself generalized contraction in gauge spaces, Fixed Point Theory, 16(2015), 393-398. 
[31] W. Takahashi, A convexity in metric spaces and nonexpansive mappings, Kodai Math. Sem. Rep., 22(1970), 142-149.

Received: June 10, 2015; Accepted: February 12, 2016. 